\title{
LENGUAJE Y MUNDO SOCIAL: LA RELEVANCIA PRAGMÁTICA DEL LENGUAJE
}

\author{
Mariela Hemilse Acevedo \\ Universidad de Buenos Aires
}

Resumen.- La intención en estas páginas es llevar a cabo una breve descripción de la vinculación que Ludwig Wittgenstein y Alfred Schutz proponen entre el lenguaje ordinario y el mundo social, intentando dar cuenta de aquellas las formulaciones que apunten a problematizar el carácter pragmáticamente determinado del significado.

Palabras clave.- lenguaje, significado, mundo social, pragmática, Wittgenstein, Schutz

Abstract.- The intention in these pages is to make a brief description of the bonding that Alfred Schutz and Ludwig Wittgenstein proposed between ordinary language and the social world, trying to account for those formulations that problematized the question the pragmatic nature of meaning.

Keywords.- language, Signification, Social World, Pragmatic, Wittgenstein, Schutz

\section{Introducción.}

La intención en estas páginas es llevar a cabo una breve descripción de la vinculación que Ludwig Wittgenstein y Alfred Schutz realizan entre el lenguaje ordinario y el mundo social, intentando dar cuenta de aquellas las formulaciones que apunten a problematizar el carácter pragmáticamente determinado del significado (esto es, que piensen los procesos de constitución de significado en relación con el mundo de la práctica social).

\section{Ludwig Wittgenstein: los juegos de lenguaje y formas de vida}

A lo largo de su obra, Wittgenstein presenta distintas formulaciones teóricas sobre la naturaleza del lenguaje. Mientras que en su Tractatus logicophilosophicus, publicado en 1921, se ocupa del lenguaje formal, en la filosofía del lenguaje que desarrolla en Investigaciones filosóficas, libro del año 1953, pasa a estudiar el lenguaje ordinario, es decir, el lenguaje tal como se lo usa en la vida cotidiana a los fines del actuar y el comunicarse socialmente. Dicho cambio de objeto de estudio da cuenta de su rechazo a la concepción nominalista o representacionalista del lenguaje y su adscripción a una concepción pragmática del lenguaje.

La concepción nominalista del lenguaje supone una relación de indicación entre la palabra y la cosa, en donde cada palabra tiene un significado ("el objeto por el que está la palabra"). Se entiende así al lenguaje como un sistema cerrado, acabado e independiente de la actividad humana. Contrariamente a esta idea, Wittgenstein planteará en Investigaciones filosóficas (1988) la imposibilidad de pensar al lenguaje independientemente de la vida social de la que forma parte. En este sentido, considerar que "imaginar un lenguaje significa imaginar una 
forma de vida" -tal como el autor nos dice- es pensar en un entrelazamiento tal entre lenguaje y práctica social que tiene como derivación en el planteo wittgensteiniano una concepción del lenguaje como práctica -mejor dicho, como conjunto de prácticas o actividades-. Y esto lo lleva a pensar al lenguaje en función de su uso (uso que está socialmente regulado, como veremos). Para desarrollar este planteo utilizará la idea de juego de lenguaje, a partir de la cual dará cuenta de la dependencia del significado respecto del contexto de su uso, y del carácter inacabado, cambiante y público del lenguaje.

El autor entiende por juego de lenguaje "al todo formado por el lenguaje y las acciones con las que está entretejido" (Wittgenstein, 1988: 25). De manera que no se puede pensar al lenguaje sino como participando de un juego de lenguaje particular; es decir, en el contexto de su uso en una práctica social determinada. Por eso entiende Wittgenstein que "el significado de una palabra es su uso en el lenguaje" (Wittgenstein, 1988: 61), de manera que las palabras terminan teniendo tantos significados como usos socialmente regidos por reglas tengan ellas en los diferentes juegos de lenguaje.

Esto da cuenta, tal como adelantamos, de la dependencia contextual del significado. Sólo en una interacción particular las palabras tienen sentido, careciendo de significado si se las considera aisladamente -en otras palabras, independientes de la interacción social de la que forman parte-. Es decir, las palabras tienen un sentido en función de un contexto que en realidad no queda reducido a la mera interacción lingüística sino que hace referencia al contexto de una actividad social particular o "forma de vida".

En cuanto a las consecuencias de un planteo como éste para una concepción del lenguaje, entendemos que, por un lado, demuestra la deficiencia para la vida práctica de una definición ostensiva del lenguaje (aquella que indica que a cada palabra le corresponde un referente), al tiempo que pone de relieve el carácter abierto y cambiante del lenguaje, siempre acompañando las variaciones de la vida social (o forma de vida) de la que es parte.

Asimismo, esta dependencia contextual del significado de las palabras también señala que toda situación particular de interacción está suponiendo que aquellos que participan de ella comparten un "conocimiento de fondo" a partir del cual es posible esa interacción. En los términos de Wittgenstein, diríamos que los sujetos pueden participar de un juego de lenguaje (y entender el significado que las palabras cobran en él) en la medida en que conozcan las reglas que rigen dicho juego; o, lo que es lo mismo, pueden participar de los juegos de lenguaje en la medida en que compartan una forma de vida.

De manera que la noción de "juego de lenguaje" le permite pensar la vinculación lenguaje-práctica-mundo social, de ahí que indique que "la expresión 'juego de lenguaje' debe poner de relieve aquí que hablar el lenguaje forma parte de una actividad o de una forma de vida" (Wittgenstein, 1988: 39). No hay lenguaje que pueda pensarse por fuera de un mundo socialmente compartido, de una intersubjetividad a partir de la cual cobre sentido. Por ello no hay lenguaje que no sea público, en tanto el uso del lenguaje es social. 
Pero, ¿qué es lo que hace que el uso del lenguaje sea social o público? Wittgenstein dirá que el uso -y por lo tanto el significado- de las palabras es social en la medida en que está regido por reglas. Como insinuamos al hablar de los juegos de lenguaje, para que las expresiones que se usan en un juego de lenguaje tengan sentido no sólo para el que las usa -el hablante- sino para los otros con quien se comunica y observan su práctica, dicho uso debe estar regido por reglas socialmente compartidas. La naturaleza social del lenguaje está dada por tratarse de una práctica regida por reglas, las cuales pertenecen a una forma de vida (Fann, 1975) (es decir, toda forma de vida comprende prácticas, usos, normas, costumbres compartidas, de manera que al actuar seguimos reglas públicas y no reglas privadas).

Esta idea de "seguir una regla" también hace referencia a un uso regular, a una costumbre o convención (a una tipicidad, dirá Schutz). Y lo central de la idea de seguir una regla es que ella denota la existencia de criterios socialmente compartidos a partir de los cuales establecer el uso correcto o incorrecto de la regla. Es decir, toda interacción humana supone este acuerdo intersubjetivo acerca de los criterios a partir de los cuales considerar el uso de una expresión como correcto o incorrecto en un contexto determinado.

Por otro lado, para Wittgenstein seguir una regla es una práctica. Esto es, uno aprende a manejar estas reglas participando de una forma de vida, en la práctica misma. Y en la medida en que "entender un lenguaje significa dominar una técnica" (Wittgenstein, 1988: 201), se entiende que la idea de seguir una regla supone la capacidad de aplicar un criterio; es decir, supone la capacidad de los sujetos que forman parte de una forma de vida de manejar, adaptar, modificar la regla de acuerdo al contexto de interacción en el que se aplica. Ello pone de relieve el carácter inacabado de la regla, que siempre se explicita y completa en el contexto de una interacción.

Pero tengamos en cuenta que esta idea según la cual los miembros de una forma de vida son capaces de manejar y aplicar las reglas al contexto en el que se encuentran actuando -habilidad que los define como miembros de una comunidad, diría Garfinkel-, no se contradice con la idea wittgensteiniana de que seguir una regla es análogo a obedecer una orden: "se nos adiestra para ello y se reacciona a ella de determinada manera" (Wittgenstein, 1988: 205). Tal como dijimos, usar el lenguaje a los fines de la comunicación con otros nos compromete a seguir ciertas convenciones en la medida en que la inteligibilidad de nuestras conductas se mide en términos de su adecuación o no a los modos de conducta comunes en una sociedad. En este sentido, algo similar plantea Norbert Elias, para quien "la fuerza imperativa del lenguaje nace del hecho de que constituye un canon unificado al que tiene que atenerse todo un grupo de individuos para que conserve su función comunicativa" (Elias, 1994: 58). Es decir, es su carácter público el que lo torna imperativo en la medida en que perdería su función y su carácter como lenguaje si sólo lo entiende un hablante. En definitiva, las convenciones sociales son las que permiten entender el significado de las palabras y las acciones porque de ellas extraen su significado. Lo mismo dirá Schutz, para quien la existencia de un conocimiento de sentido común sobre el mundo de la vida cotidiana compartido por los 
miembros de un grupo social es el presupuesto de toda acción e interacción social.

\section{Alfred Schutz: el mundo social y el conocimiento socialmente compartido}

En la perspectiva teórica de Alfred Schutz sobre la constitución significativa del mundo social también podemos rastrear, tal como lo hemos hecho con el planteo de Wittgenstein, el vínculo entre lenguaje y mundo social, el papel del lenguaje en la construcción de las tipificaciones de sentido común, así como el carácter pragmáticamente orientado y socialmente compartido de las construcciones significativas. Sus nociones de mundo de la vida cotidiana y construcciones objetivas de sentido común, así como la idea de significatividad, aparecen como centrales para abordar estas cuestiones.

Para Schutz, el mundo de la vida cotidiana se presenta a los hombres como un mundo a ser experimentado e interpretado, donde toda experiencia e interpretación se basa en un acervo de experiencias previas sobre él -sean estas propias o heredadas- que funcionan como esquemas de referencia en forma de "conocimiento a mano". Y este "conocimiento a mano" se organiza en tipos, siendo el lenguaje un sistema de tipificaciones por excelencia, el cual es central para la conformación de un ambiente comunicativo común.

A partir de este acervo de conocimiento a mano es posible la interpretación de los hombres del mundo social así como su ejecutar en él. Podemos decir entonces que las construcciones de sentido común tienen una finalidad práctica, son construidas a los fines de actuar, pensar y vivir en el mundo social. Los hombres en la actitud natural no tienen un interés contemplativo respecto del mundo sino eminentemente práctico: por ello el mundo de la vida cotidiana es el escenario y el objeto de las acciones e interacciones, y donde no sólo se actúa sobre las cosas inanimadas sino también sobre los semejantes (Schutz, 1974: 198).

De lo dicho hasta aquí se desprende que este mundo es para los hombres, desde el principio, un mundo intersubjetivo y cultural es decir, un mundo que se comparte con otros y que es significativo no sólo para cada hombre individualmente sino para un "Nosotros" que habita conjuntamente ese mundo. Tal como lo adelantábamos, el mundo de la vida cotidiana es un universo de significación al que debe interpretarse para conducirse en él, y cuya significación se instituye a partir de la propia práctica humana. Análogamente al planteo de Wittgenstein, las construcciones significativas (entre ellas, las tipificaciones propias del lenguaje común) no son independientes de las prácticas humanas. Al respecto, dice Schutz: "todos los objetos culturales herramientas, símbolos, sistemas de lenguaje, obras de arte, instituciones sociales, etc.- señalan en su mismo origen y significado las actividades de sujetos humanos. (...) Por la misma razón, no puedo comprender un objeto cultural sin referirlo a la actividad humana en la cual se origina" (Schutz, 1974: 41). 
Ahora bien, en la medida en que el mundo social es un mundo intersubjetivo, el conocimiento que se tenga de él (los esquemas de referencia a partir de los cuales se puede interpretar y orientar el ejecutar diario) no puede ser privado sino que también debe ser un conocimiento común, público, intersubjetivo. Esta socialización del conocimiento Schutz la va a pensar a partir de tres cuestiones:

-Por un lado, a partir de lo que denomina la socialización estructural del conocimiento o reciprocidad de perspectivas, sustentada en la idealización de la intercambiabilidad de los puntos de vista y la idealización de la congruencia del sistema de significatividades. Estas idealizaciones permiten superar las diferencias en las perspectivas individuales ("a los fines prácticos") a partir del presupuesto de que todos los que forman parte de un "nosotros" comparten sustancialmente un sistema de significatividades (suficientemente como para poder interactuar en el mundo). Este conocimiento compartido del mundo social, dice Schutz, reemplaza a los objetos de pensamiento privados construidos por los hombres de acuerdo a sus situaciones biográficas particulares, sus propósitos y sistemas de significatividades. Las construcciones de los objetos de pensamiento de sentido común, entendido éste como un conocimiento objetivo y anónimo (separado de la definición de la situación de los individuos particulares), es un conocimiento presupuestamente compartido por todos: "lo que se supone conocido por todo el que comparta nuestro sistema de significatividades es el modo de vida que los miembros del endogrupo consideran natural, bueno y correcto" (Schutz, 1974: 43).

-Por otro lado, teniendo presente que el conocimiento de sentido común es de origen social, en la medida en que la mayor parte del conocimiento que se tiene del mundo es un conocimiento heredado. Así, considerando que por medio de la aculturación por la lengua materna se adquieren las tipificaciones de sentido común, el lenguaje aparece como el medio tipificador por excelencia: por medio de él se elaboran "construcciones típicas de acuerdo con el sistema de significatividades aceptado por el punto de vista anónimo unificado del endogrupo" (Schutz, 1974: 44). Tal como vimos con Wittgenstein, el lenguaje cotidiano es inseparable del sistema de significatividades propio de un grupo que hace que ciertos aspectos del mundo se institucionalicen, generalicen y tipifiquen.

-Finalmente, considerando que el conocimiento se encuentra desigualmente distribuido al interior de un grupo social, al tiempo que es un conocimiento con distintos grados de claridad y familiaridad. Por su parte, el conocimiento de sentido común incluye el conocimiento de estas diferencias y es capaz de atribuir competencias diferenciales a los distintos miembros de un grupo.

Pero para comprender esta idea de "reemplazo" de las construcciones de significado privadas por las construcciones objetivas de sentido común, señalemos primero cómo piensa Schutz la experiencia de los individuos en la vida social. Para él, la experiencia del mundo se encuentra biográficamente determinada. La situación biográfica configura el acervo de conocimiento a mano de las personas (que remite a una historia particular), al tiempo que establece los sectores del mundo que serán significativos a los fines prácticos del sí-mismo ejecutante en la vida cotidiana. Tal como dijimos al comienzo, el 
mundo de la vida cotidiana es el ámbito del ejecutar humano, es el ámbito en el que los hombres llevan a cabo sus proyectos y planes de vida. Y son los "propósitos a mano" los que definen el sistema de significatividades de cada individuo, la esfera del mundo que tiene relevancia práctica en la actitud natural.

Estas consideraciones demuestran que la comprensión del mundo sólo se da en el grado necesario para poder actuar en él y operar sobre él. En otras palabras, el pensar, en la actitud natural, está motivado pragmáticamente (está determinado por un motivo pragmático) (Schutz y Luckmann, 1977: 28). De ahí que Schutz señale que "una decisión interpretativa es motivacionalmente importante para el hombre. Esto significa que es importante para su conducta, para su acción y, finalmente, para su manera de vivir" (Schtuz y Luckmann, 1977: 207). Al igual que ocurría en el planteo wittgensteiniano, nuevamente hay una estrecha relación entre los esquemas de interpretación y la práctica: son los propósitos a mano, las motivaciones, las cuestiones que definen en qué medida se realizará la activación del tipo, es decir, qué grado de determinación y familiaridad deberán presentar los elementos del acervo que tienen significatividad interpretativa para cada momento de acción e interacción. Y es así como la "medida de la coincidencia" entre el tema y el acervo que será suficiente para dominar la situación estará también determinada motivacionalmente. Por eso puede decirse que en base a los intereses prácticos y propósitos a mano se establece en cada situación lo presupuesto y lo problemático del mundo de la vida cotidiana (Schutz y Luckmann, 1977: Cap. I, B), siendo esta distinción pragmáticamente determinada y no determinable de antemano.

Ahora bien, habíamos dicho que el mundo de la vida cotidiana era un mundo intersubjetivo, que "el mundo del ejecutar es la realidad dentro de la cual se hace efectiva la comunicación y el juego de las motivaciones mutuas" (Schutz, 1974: 213). De manera que, a los fines de la acción y la interacción social, los actores deben orientar sus acciones según ciertos patrones socialmente aprobados como reglas de conducta por el endogrupo al que ellos pertenecen, de manera que su conducta no tenga sentido sólo para ellos sino para el resto de los individuos con los que actúa u observan su acción. Esto es, para que su conducta sea interpretada por el resto como conducta razonable, debe seguir reglas y recetas socialmente aprobadas para afrontar problemas típicos aplicando medios típicos para logras fines típicos (es decir, hacer lo que cualquiera del grupo haría si estuviera en su lugar).

De manera que la interacción supone que los esquemas interpretativos de ambos sujetos en interacción coincidirán a todos los fines prácticos, o "sustancialmente" (Schutz, 1974: 288). Es decir, Schutz reconoce que es imposible que los esquemas interpretativos de los sujetos logren una identidad total (en la medida en que están determinados por la situación biográfica y el sistema de significatividades que esta origina), pero sin embargo la comunicación es posible y eficaz para muchos fines prácticos. Lo que ocurre es que "todo proceso de comunicación, para ser eficaz, debe suponer un conjunto de abstracciones o estandarizaciones comunes" (Schutz, 1974: 288), y la tipificación es la forma de abstracción que conduce a la conceptualización más 
o menos estandarizada del pensar de sentido común. En la medida en que la comunicación sólo es posible a partir de tipificaciones, abstracciones y estandarizaciones, el lenguaje es central para la vida social puesto que a través de él se llevan a cabo estas operaciones: por medio del lenguaje se construyen y transmiten las tipificaciones sociales.

\section{A modo de cierre.}

Siguiendo las formulaciones de Schutz, las tipicidades del sentido común -entre ellas, las tipicidades lingüísticas- son construidas por sujetos con finalidades prácticas en el mundo social, que se encuentran en una situación de interacción y donde deben regirse por pautas de interacción típicas a fin de entrelazar los motivos para y porque de los interactuantes (y alcanzar la idealización de la reciprocidad de motivos).

El uso de estas tipificaciones de sentido común es lo que permite crear y recrear la normalidad percibida del mundo del ejecutar cotidiano. Estas tipificaciones -al igual que las reglas de las que habla Wittgenstein- se aplican regularmente sin conciencia explícita (aunque susceptibles de explicitaciones) a los fines de mantener y confirmar el fluir de la vida cotidiana. Ocurre así que, tanto en el planteo de Ludwig Wittgenstein como de Alfred Schutz, las construcciones tipificadas del lenguaje surgen como necesidad práctica del mundo intersubjetivo al tiempo que se institucionalizan y adquieren una objetividad que las vuelve imperativamente necesarias para la comunicación social. 


\section{Bibliografía:}

(1994) ELÍAS, Norbert, Teoría del símbolo. Un ensayo de antropología cultural, Editorial Península, Barcelona.

(1975) FANN, K. T., El concepto de filosofía en Wittgenstein, Editorial Tecnos, Madrid.

(1974) SCHUTZ, Alfred, El problema de la realidad social, Editorial Amorrortu, Buenos Aires.

(1977) SCHUTZ, Alfred y LUCKMANN, Thomas, Las estructuras del mundo de la vida, Editorial Amorrortu, Buenos Aires.

(1988) WITTGENSTEIN, Ludwig, Investigaciones filosóficas, Editorial Crítica, Barcelona. 